\title{
New name, same values
}

This journal's guiding philosophy is to publish academic research that enriches our collective understanding of people, society and ideas. To ensure that we articulate our mission to the many communities we serve, clearly and straightforwardly, this journal will now be published as Humanities \& Social Sciences Communications. This decision does not reflect any change to our scope, values or editorial standards; rather, it is done in a spirit of reaffirming our core mission.

\section{Into a new era}

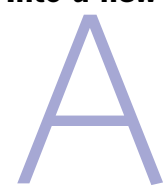

cademic journals should grow and evolve in response to the research communities they serve. Publishers and editors may set about achieving this, with a requisite agility, in numerous ways. A journal's scope may be modified over time and its coverage (re) focused to align with emerging trends or to meet new community expectations. Editorial policies and processes may be adapted to respond to new realities, challenges and innovations. Beyond these fundamental and substantive considerations, there is also the issue of what name an academic journal takes. Although often taken for granted, a publication's name or title is an important signal and indicator of its underlying philosophy, vision and ethos.

Since it began publication in 2015 this journal-operating as Palgrave Communications-has succeeded in providing a rigorous and dynamic outlet for the publication of research arising in all areas of the humanities, social and behavioural sciences.

To build on these strong foundations, and to ensure we fully convey our ethos and vision to the communities in our remit, this journal will now operate as Humanities \& Social Sciences Communications.

It was once famously said that 'for things to remain the same, everything must change' (di Lampedusa, 1958). Indeed, while our name change, and accompanying new-look redesign, could intimate 'everything has changed', our intention is that those fundamentals that most matter to authors and readers 'remain the same': namely, our commitment to high editorial standards, adhering to robust editorial policies and to offering a quality and responsive service.

Our decision to operate under a new name does not reflect a shift in our scope, values or editorial standards; rather, it is done in a spirit of reaffirming our editorial mission statement.

This journal draws on the expertise and best practice of all the imprints within the broad Springer Nature family, including Palgrave Macmillan, from which it took its original name.

\section{Our mission statement}

Humanities \& Social Sciences Communications is a broad and inclusive journal. We are committed to publishing academic research that engages with all aspects of the study of society and the ways in which we behave, engage with and influence the world around us, as well as how we process, document and interpret our experiences. We publish research outputs of all types-whether theoretical, methodological, qualitative or quantitative-provided they meet our criteria for publication (Editorial, 2020). This extends to negative results and replication studies, reflecting the reality that academia can advance by both discovery and innovation, but also (dis)confirmation. As a multidisciplinary journal we want to publish the scholarship that matters to each core field within our scope, whether it be niche in focus or of wider appeal and application, and irrespective to whether it represents an incremental contribution or a more significant advance. We particularly welcome research that informs or 
interrogates policy-making or which engages with urgent societal issues, such as those embodied in the UN's Sustainable Development Goals. We recognise that research cannot be placed neatly and arbitrarily into discrete 'disciplinary buckets', and that traditional boundaries and confines are increasingly dissolving. We therefore encourage the submission of scholarship that combines theory, methods or analytical frameworks from two or more disciplines. This inclusivity extends to research influenced by, or even originating in, the physical, clinical or environmental sciences, but which nonetheless makes a meaningful contribution to advancing our understanding of people, society and ideas. Fast-evolving interdisciplines, such as, for instance, the medical humanities, computational sociology and the digital humanities, are cases in point.

Our commitment to providing an outlet for topical, newly emerging and disciplinetranscending research is reflected in the thematic article collections we have published to date. These collections provide rich repositories for fresh thinking, including research themes that may not find a natural home in more narrowly defined or niche journals. Our flexible publishing model means that these collections have space to grow and evolve over extended periods of time, in a way that traditional static 'special issues' cannot.

\section{Open research}

This journal champions open access as a publishing model that brings numerous benefits to readers, authors and wider society. We believe that by facilitating the publication of quality research, we can make a meaningful contribution to supporting, promoting and increasing uptake of open access publishing in the humanities, social sciences and allied areas. We are also committed to supporting related initiatives, such as 'open data'. Our research data policy expects authors, where appropriate, to share their research 'data'-taken to mean any materials underpinning a body of research, whether qualitative or qualitative in nature. Authors are required to provide a statement of data availability, outlining to readers how and where the data can be accessed. By requiring evidence of data sharing we hope to encourage the open sharing, reuse and citation of research data and materials, thus promoting transparency and reproducibility in academic research (Editorial, 2015).

\section{Onwards...}

As we move forward, now operating under a new name, this journal will continue to strive to deliver on the mission set out here. Ultimately, we believe that genuine progress in understanding how we engage with each other and make sense of the world can only be achieved through a multi- and interdisciplinary endeavour. Humanities \& Social Sciences Commu- nications aims to support and foster that effort.

Published online: 17 June 2020

\section{References}

di Lampedusa GT (1958) Il Gattopardo. Feltrinelli (Milano)

D’Oca G, Hrynaszkiewicz I (2015) Palgrave Communications' commitment to promoting transparency and reproducibility in research. Palgrave Commun 1:15013. https://doi.org/10.1057/palcomms.2015.13

Editorial (2020) Our criteria for publication. Palgrave Commun 6:9. https://doi.org/10.1057/s41599. 019-0382-y

\footnotetext{
Open Access This article is licensed under a Creative Commons Attribution 4.0 International License, which permits use, sharing, adaptation, distribution and reproduction in any medium or format, as long as you give appropriate credit to the original author(s) and the source, provide a link to the Creative Commons license, and indicate if changes were made. The images or other third party material in this article are included in the article's Creative Commons license, unless indicated otherwise in a credit line to the material. If material is not included in the article's Creative Commons license and your intended use is not permitted by statutory regulation or exceeds the permitted use, you will need to obtain permission directly from the copyright holder. To view a copy of this license, visit http:// creativecommons.org/licenses/by/4.0/.
}

(C) Springer Nature Limited 2020 